\title{
Risk factors for the metabolic syndrome in contemporary China
}

C.M. Schooling *

Department of Community Medicine and School of Public Health, The University of Hong Kong,

21 Sassoon Road, Pokfulam, Hong Kong SAR, China

E-mail address: cms1@hkucc.hku.hk. 


\section{Introduction}

Until the $18^{\text {th }}$ century levels of economic development were fairly similar in Europe, India and China. ${ }^{1}$ Thereafter Europe and North America experienced the industrial revolution and sustained, but fairly gradual, economic growth. In contrast, industrialization and associated economic growth did not take place in China until well into the second half of the $20^{\text {th }}$ century. ${ }^{1}$ Some improvements in living standards due to more equitable distribution may have taken place after the establishment of the People's Republic of China in 1949, followed by some limited economic growth which accelerated at the end of the 1970s. ${ }^{1}$ As a result, China, like other developing countries, is currently experiencing a more rapid and compressed epidemiologic and nutritional transition than that described by Omran even in the accelerated model, with many changes taking place simultaneously. The population health implications of this rapid and compressed transition are not necessarily the same as the implications of a gradual transition. Some experiences in China today may be more akin to experiences in western populations at the start of the industrial revolution, for which the historical record is almost completely absent, whilst observations from a developed country setting may not translate directly to contemporary China. Nevertheless, these related transitions in China over the last half century encompass the expected changes: a sharp decline in infectious diseases evident by $1980,{ }^{2}$ increased life expectancy from 39 in 1949 to 69 by $1995,{ }^{2}$ dramatically lower fertility, increased availability of food ${ }^{3}$ and reduced physical activity. As predicted these changes have recently resulted in increased rates of "man made and degenerative diseases", such as Type 2 diabetes and cardiovascular diseases. Diabetes prevalence in China has risen from about $1 \%$ in people aged $\geq 30$ years in $1980,{ }^{4}$ to levels more similar to Europe and North America, i.e. 5.5\% in the 35 to 74 years age group by $2001,{ }^{5}$ although rates are higher (about 10\%) in some developed Chinese populations, e.g. in Singapore. ${ }^{6}$ Cardiovascular diseases are now the leading causes of death in China, ${ }^{7}$ although the profile of cardiovascular disease in China is different from that in Europe and North America, with more cerebrovascular disease, more hemorrhagic strokes and less coronary heart disease; ${ }^{8 ; 9}$ more akin to the pattern historically seen some Western countries. ${ }^{9 ; 10}$

The prevalence of a constellation of risk factors for diabetes and atherosclerotic cardiovascular disease, the metabolic syndrome, provides a useful sentinel for the epidemic of man-made and degenerative diseases emerging in China. The metabolic syndrome is usually characterized by central obesity, hypertension, hyperglycemia, raised triglycerides and reduced HDL-cholesterol with the International Diabetes Federation (IDF) stipulating that the presence of central obesity and at least two other abnormalities constitute the metabolic syndrome whilst the National Cholesterol Education Program- Adult Treatment Panel III (NCEP-ATPIII) stipulates that the presence of any three (or more) is sufficient. ${ }^{11}$ The World Health Organization definition also includes insulin resistance, and so is less used. The cut-offs for each criteria have been reviewed and revised with ethnic specific criteria introduced for waist circumference. Currently the thresholds for central obesity are waist circumference $\geq 80 \mathrm{~cm}$ (females) or $90 \mathrm{~cm}$ (males) in Chinese, for hypertension are systolic and/or diastolic blood pressures $\geq 130 / 85 \mathrm{~mm} \mathrm{Hg}$ or relevant 
treatment, for hyperglycemia are fasting plasma glucose $\geq 5.6 \mathrm{mmol} / \mathrm{L}$ (IDF) or $\geq 6.1 \mathrm{mmol} / \mathrm{L}$ (NVEPATPIII) or treatment of type 2 diabetes), for triglycerides are fasting plasma triglycerides $\geq 1.7 \mathrm{mmol} / \mathrm{L}$ or specific treatment) and for reduced HDL-cholesterol are fasting HDL-cholesterol $<1.03$ (males) or 1.29 mmol (females) or specific treatment). ${ }^{11}$ In western populations, presence of the metabolic syndrome is consistently associated with excess risk of diabetes (190\%), of cardiovascular diseases (53\%) and of cardiovascular mortality (between $65 \%$ and $90 \%$ ). ${ }^{12-14}$ Despite differences in prevalence similar findings would be expected in Chinese, and have been seen in Hong Kong Chinese men, ${ }^{15}$ although in Beijing the metabolic syndrome was better at predicting diabetes. ${ }^{16}$ Thus, the metabolic syndrome is not always a more useful predictor of diabetes or cardiovascular disease than its individual risk factors alone, ${ }^{17}$ or their summation into long-standing risk scores, such as the Framingham score.$^{18}$ Hence, the status of the metabolic syndrome as a simple clinical tool for identifying and potentially treating at risk individuals is controversial, with some arguing that it has no clinical utility beyond its constituent parts, ${ }^{19}$ and others arguing that it helps promote a more holistic approach to tackling the common underlying risk factors. ${ }^{20} \mathrm{As}$ a result a wider concept of cardiometabolic risk, including other measures such as C-reactive protein, fibrinogen, plasminogen activator inhibitor-1 and apolipoprotein B, is emerging. However, as yet there is no clearly operationalized definition of a cardiometabolic risk syndrome, so this review focuses on the metabolic syndrome.

The epidemic of the metabolic syndrome in China is recent, although exactly when it arose is difficult to assess, because of the lack of trend data. Nevertheless, prevalence of the metabolic syndrome in China is approaching levels seen in western countries, although comparisons are hampered by the use of ad-hoc samples and differing definitions. In nationally representative samples, from similar time periods (around 2000), using the same definition of the metabolic syndrome with internationally recommended ethnically appropriate criteria for central obesity, prevalence of the metabolic syndrome in USA men and women aged $\geq 30$ years was about $40 \%$ and $44 \%$ respectively ${ }^{21}$ compared with $18 \%$ and $29 \%$ in Chinese men and women aged 35-74 years, ${ }^{22}$ with higher rates in urban areas and the north. ${ }^{22}$ However, higher prevalence in Chinese women compared with men is at variance with the higher rate of premature coronary heart disease in men than women, ${ }^{9}$ and may be the result of using a poor proxy of central obesity in men.

The metabolic syndrome can be seen as both a convenient shorthand for identifying people at higher risk of diabetes and cardiovascular diseases who should receive integrated management, and a form of metabolic dysregulation, with a common underlying pathophysiological abnormality. Initially insulin resistance or hyperinsulimia was seen as the underlying abnormality, because empirically most people with the metabolic syndrome had one of these. ${ }^{23}$ However, the role of insulin resistance is disputed because there is little evidence that reducing insulin resistance improves any component of the metabolic syndrome apart from glucose intolerance, with the causal role of insulin resistance in hypertension perhaps being least clear. ${ }^{24}$ More recently, abdominal obesity has been seen as the underlying abnormality, ${ }^{25}$ because visceral 
adipose tissue is a source of factors, such as free fatty acids or tumor necrosis factor-alpha, that impair insulin action in skeletal muscle. However, abdominal obesity does not appear to be a necessary condition for IHD in the Chinese men with the metabolic syndrome. ${ }^{26}$ Currently, there are three potential etiologies for the metabolic syndrome, i.e. insulin resistance, central obesity and other factors, including inflammation. The longitudinal studies which might help distinguish these etiological pathways have yet to be carried out. Instead, statistical techniques, such as factor analysis, have been applied to the biological parameters defining the metabolic syndrome to determine the number of under-lying constructs, which may potentially correspond to the underlying pathophysiological abnormalities. Most studies, including studies in Chinese, have identified several factors ${ }^{27,28}$ potentially indicating a number of distinct underlying abnormalities, although a recent study found only one factor ${ }^{29}$ potentially indicating that the metabolic syndrome is a distinct entity with a single underlying factor that influences expression of all the features of the metabolic syndrome. However, this finding could also have been the result of the small number of biological parameters used in the factor analysis. Such uncertainty about the pathogenesis of the metabolic syndrome makes it difficult to identify causal mechanisms and risk factors from a physiological perspective and hence to identify the relative importance of current environment, population genetics and influences over the life course.

\section{Macro-environment}

Increased availability of food in China since the establishment of the People' Republic of China in 1949 has been successful in reducing under-nutrition and hunger, despite some periods of great hardship in the late 1950s and 1960s during the Great Leap Forward and the Cultural Revolution. Food availability has increased markedly in China, particularly since $1962,{ }^{3}$ with the largest increases in cereal consumption and sugar before about $1985,{ }^{2}$ followed more recently by increases in consumption of vegetable oil, edible oil and animal source foods, ${ }^{2}$ although more recently (i.e. from 1982 to 2002) average daily calorie intake has stablised. ${ }^{30}$ Long-term trends in physical activity in China are less well-documented. However since 1949 there has been increasing urbanization, such that the proportion of the population living in urban areas increased from $10.6 \%$ in 1949 to $36.2 \%$ in $2000,{ }^{31}$ with corresponding reductions in occupational physical activity, which can be a key contributor to energy balance. Reductions in potentially beneficial commuting physical activity would be expected from the increasing number of vehicles in China since $1949 ;{ }^{32}$ where vehicle ownership is associated with weight gain. ${ }^{33}$ Many domestic changes associated with economic development, such as labor saving devices, television and even a more comfortable ambient temperature may have also contribute to reduced energy expenditure. ${ }^{34}$ Given, the historically recent transition in China from relatively short lives dominated by manual labor, there may be less of a tradition and culture of leisure exercise or sporting participation, and there has been a shorter period of historic time in which to build-up the relevant infrastructure of recreational facilities. Undeniably an imbalance of energy intake to energy expenditure in a more obesogenic environment requiring less physical activity is a proximal determinant of the recent increase in the metabolic syndrome in China. Positive energy imbalance results in weight gain; 
even in the very lean small increases in weight are associated with hypertension, hyperglycemia, dyslipidemia. ${ }^{35}$ Moreover, reduced energy intake and/or increased energy output have been shown to improve metabolic profile in several trials. ${ }^{36 ; 37}$ However, energy imbalance is only one facet of macroenvironmental change towards a more obesogenic environment driven by socio-economic development. With increasing wealth there are many other changes which may impact the risk of the metabolic syndrome, such as greater availability of and access to a wider range of foods, cigarettes and alcohol. Moreover, all of these changes take place within a social context whose structure may impact the level of risk and which groups are at greatest risk.

Dietary composition

Over and above energy imbalance, two facets of dietary composition closely linked to the clinical manifestations of the metabolic syndrome have been extensively investigated, i.e. dietary fat and glycemic index. Observational studies of diet are difficult to interpret, due to the practical difficulty of obtaining accurate and comprehensive records of dietary intakes, potentially compounded by under reporting of total energy intake and of foods considered to be unhealthy, ${ }^{38 ; 39}$ although such biases in dietary reporting may be less of a problem in China, where notably accurate reports of energy intake have been obtained. ${ }^{40}$ Randomized control trials are expensive, rare, short-term, generally emphasis aspects of western diets, such as the consumption of olive oil or low-fat dairy products, and often include a variety of dietary changes, so it is difficult to know which are the key items that might translate into a different setting with different dietary patterns. Nevertheless, there is a clear consensus that diets with a higher proportion of saturated fats are harmful ${ }^{41}$ and may be associated with the development of the metabolic syndrome, ${ }^{42}$ which can be reversed by reducing the proportion of saturated fats. ${ }^{43}$ Replacement of saturated fats with other fats may be more beneficial than replacement with simple carbohydrates, because diets with a high glycemic index may increase the risk of developing type 2 diabetes. ${ }^{44}$ Human trials suggest that diets low in carbohydrates or high in complex carbohydrates are associated with a healthier metabolic profile. ${ }^{36}$ It has also been suggested, based on ecological evidence, that a traditional Chinese diet, low in fat and protein, results in a higher (and hence protective) metabolic rate. ${ }^{45}$

In the Chinese context, where most cooking oil is mono-unsaturated (peanut or rapeseed) or polyunsaturated (corn and soybean), ${ }^{46}$ the most significant change in dietary composition is probably an increase in the proportion of animal source foods, either from meat or dairy products, and possibly an increase in more highly processed foods. Animal source foods have long been regarded as a useful source of protein and trace elements. Epidemiological studies suggest a high meat intake may be associated with the metabolic syndrome, ${ }^{47}$ although in the Shanghai Women's cohort higher intake of unprocessed meat protected against the development of diabetes. ${ }^{48}$ However there was no dose-response and the analysis was adjusted for total calories and vegetables, which could mean that higher meat intake was a proxy for lower rice intake, and protective for that reason. To date there is little evidence that milk or dairy produce intake 
increases metabolic risk, ${ }^{49}$ despite, inevitably weak, ecological evidence to the contrary. ${ }^{50}$ However, almost all the evidence comes from populations where dairy products are a normal part of the diet and the comparisons are between levels of dairy intake, whereas the relevant comparison for China is between those who do and do not use dairy products. Moreover, due to genetic differences the sustained ability to digest the milk sugar lactose throughout adulthood (i.e. lactase persistence) is uncommon in China ${ }^{51}$ and could moderate the effect of dairy products. Overall changes in dietary composition taking place in China may have both positive and negative effects on the metabolic syndrome, positive through increasing dietary variety and possibly placing less emphasis on rice and whilst potentially negative through higher intakes of meat, saturated fats or processed foods.

Tobacco and alcohol

Economic growth in China has enabled other changes in lifestyle, such as more widespread use of cigarettes and alcohol. The average number of manufactured cigarettes per man went up 15 times between 1952 and 1996 in China, from one to 15 cigarettes per man; although smoking is rare amongst Chinese women. ${ }^{52}$ Similarly, per adult pure alcohol consumption in China increased from 1.03 liters in 1970 to 5.17 liters in $1996 .^{53}$ Again, use of alcohol is rare in Chinese women, both in China ${ }^{53}$ and in more developed Chinese settings, such as Hong Kong. Despite, the rise and fall of the smoking epidemic seen in developed western countries in men followed by women, there are as yet little indication of a female smoking epidemic emerging in developed Chinese settings, such as Hong Kong. ${ }^{54}$ Smoking is a well established risk factor for cardiovascular diseases and diabetes, and as would be expected has been shown to be associated with the development of the metabolic syndrome. ${ }^{55}$ The role of alcohol is more controversial, with a $\mathrm{U}$ or $\mathrm{J}$ shaped association between alcohol use and cardiometabolic risk often observed, such that moderate, but not heavy, alcohol use may appear protective. Patterns of alcohol use may change with ill-health making cross-sectional studies open to reverse causality. Prospective studies have the advantage of temporal sequence, potentially reducing reverse causality. Few studies have examined the prospective association of alcohol use with the metabolic syndrome, with somewhat mixed results. However, moderate alcohol use has been found associated with lower mortality from ischemic heart disease (IHD),${ }^{56}$ ischemic stroke ${ }^{57}$ and diabetes ${ }^{58}$ but not hemorrhagic stroke. ${ }^{57}$ However in observational studies it is difficult to discern whether the effect of alcohol is due to alcohol or other attributes of moderate alcohol users. Both of the prospective studies to date examining the impact of alcohol use on mortality in Chinese found moderate use protective against $\mathrm{CHD}^{59}$ or cardiovascular disease,$^{60}$ although one also found similar benefits of alcohol for accidents ${ }^{59}$ suggesting perhaps a systematic difference between moderate alcohol users and non-uses. More limited, but possibly more reliable, evidence largely from randomized control trials suggests that alcohol increases blood pressure, ${ }^{61}$ has no effect on insulin sensitivity, ${ }^{62}$ but improves lipid profile (triglycerides and HDL-cholesterol). ${ }^{62 ; 63}$ These differing effects of alcohol on various aspects of the metabolic syndrome suggest that overall moderate alcohol use might be having a largely neutral effect on the metabolic 
syndrome in men, but due to the low levels use it is unlikely to be playing a role in the increase in the metabolic syndrome in women.

Social context

The differing use of tobacco and alcohol by men and women in contemporary China clearly indicates the impact of cultural context on lifestyle; these are but one example, which operates within the broader context of the impact of social structure on health. There are most likely others. For example, it is quite possible that within a culture with, until recently, high levels of food insecurity, adiposity is seen as projecting a socially desirable image of wealth and success. However, with the progress of the epidemiologic transition metabolic risk often become concentrated amongst the less advantaged. First, the less advantaged may have poorer access to all aspects of preventative health, including a healthy diet and recreational facilities. Second, there may be social patterning of shared values and culture, and hence the acceptability of a more or less health conscious lifestyle. Third, the physiological consequences of the stress generated by lower absolute or relative social position may increase metabolic risk, ${ }^{64665}$ whilst a more socially cohesive society may be protective ${ }^{66}$ Currently in China, with its recent epidemiological transition, lower social position is not consistently associated with poorer metabolic health, ${ }^{67,68}$ particularly in men. ${ }^{69}$ However, as elsewhere low social position could become a more important social determinant of metabolic health in China as the epidemiological transition progresses. Hence the need for population wide, possibly regulatory, public health interventions, most clearly illustrated in global tobacco control policies, but also recently extending beyond food safety in nutrition, such as action on trans-fats.

\section{Genetics and Epigenetics}

The epidemic of the metabolic syndrome in China has emerged over about 20 years, during which time the genetic make-up of the population is unlikely to have changed. Undoubtedly, genetic differences may make some individuals or populations more susceptible. Family and twin studies have shown a heritable

contribution to the metabolic syndrome. ${ }^{70 ; 71}$ However, its complexity and the lack of a clear aetiological framework make the identification of candidate genes based on functionality difficult. As yet, genes responsible for the metabolic syndrome have not been unequivocally identified, although various possibilities have been identified. There has been greater success in identifying genes associated with specific components, such as the FTO (fat-mass and obesity-associated) gene however the FTO risk variant may be less common in Chinese populations, ${ }^{72}$ where its role has been questioned. ${ }^{73}$ Genetic analysis can be unreliable and prone to the false positive findings because of the very large number of possible associations considered.

Considered at a population level, currently, non-European ethnic groups appear more prone to central adiposity $^{74}$ and hence its metabolic consequences. Neel's 'thrifty genotype' hypothesis suggested that over human history famines had selected for genes enabling efficient food storage, i.e. the 'thrifty genotype', 
which by postulating different selection pressures by ethnic group also explains differences between populations of European descent and others. However, the evidence that these famines took place, that they preferentially increased mortality in thinner people of reproductive age or differed between ethnic groups is increasingly being questioned. ${ }^{75}$ As yet no relevant genes for the thrifty genotype have been clearly identified. Alternatively, the recent re-discovery of nonMendelian heritable changes in gene expression driven by the environment in previous generations, i.e. epigenetics, suggests yet another pathway by which population history may leave an imprint on population health and also result in differences between individuals. Epigenetic mechanisms evolved to maximize maternal-offspring co-adaptations, which in species where the offspring continue to acquire resources from their parents in early life, would include parental regulation of post-natal as well as pre-natal growth. ${ }^{76}$ Epigenetic effects can extend over generations. Epigenetically determined growth regulation during the growth phases of greatest dependence (infancy and childhood) would ensure the offspring's demands did not outstrip the mother's resources. There is some very limited empirical evidence of epigenetic constraints on linear growth during infancy and childhood (i.e. of the legs) in Chinese populations with a short history of economic development. ${ }^{77}$ Impacts on long-term health have not been investigated, although there are potential physiological pathways that might generate a transitory epidemic of diabetes and associated metabolic disease for the first few generations to experience sustained economic development. Better living conditions in the current generation coupled with epigenetic constraints on infant and childhood linear growth resulting from limited living conditions in earlier generations, would be expected to result in more pubertal linear growth, ${ }^{78}$ as has been seen in the current generation of southern Chinese compared with earlier generations. ${ }^{79}$ Relatively or absolutely more pubertal linear growth is consistently associated with diabetes and/or insulin resistance, ${ }^{79-81}$ probably due to alterations to the GH/IGF- 1 axis,${ }^{80}$ whose effects might be exacerbated by lack of compensating muscle mass from longer legs. However, living in economically developed conditions over generations would reduce epigenetic constraints on early linear growth and correspondingly reduce relative pubertal linear growth and risk of diabetes. Whether transient epidemics of diabetes have previously occurred in other groups undergoing rapid economic development is lost in the mists of time. Nevertheless, something similar may have occurred following the Jewish exodus from Russia in the late $19^{\text {th }}$ century to the north-eastern US cities, where in the early $20^{\text {th }}$ century Jews were transiently more prone to diabetes. ${ }^{82}$ Thus the current epidemic of diabetes in developing or recently developed populations such as Chinese may partially be a 'first few generations through' effect generated by rapid environmental change causing disproportionate growth against a background of epigenetic constraint on infant and childhood growth. Such a theory would provide an alternative conceptualization of ethnic differences in susceptibility to diabetes and the metabolic syndrome as the product of differences in population wide experiences of economic development over historical time, however as yet it is speculative.

\section{Life course influences}


Life course influences on health have long been recognized, but their prominence has varied with academic discipline and time. In the last 20 years, Barker's work, coupled with the difficulty of modifying adult behavior has re-ignited interest in the developmental origins of health and disease. Despite two decades of intensive research the developmental origins of metabolic disease remain controversial with the underlying physiological pathways only beginning to be elucidated. Much attention has been focused on Barker's fetal origins hypothesis, which interpreted the original empirical observations of associations between low birth weight and adult metabolic disease, as a fetal exposure, despite intervening exposures. Moreover, the effects of low birth weight on adult health are relatively small; for example in the well-established association between birth weight and blood pressure, results from meta-analysis suggest that a very large increase in birth weight of one kilogram would reduce adult systolic blood pressure by less than $1 \mathrm{~mm}$ Hg. ${ }^{83}$ Evidence from experiments designed to test the fetal origins hypothesis has highlighted the role of nutritionally driven post-natal growth as a possible missing link in the observed relation between birth weight and adult metabolic disease. Currently, the original 'fetal origins' hypothesis has been subsumed within a broader theoretical framework emphasizing the role of 'mismatch' between fetal and later life environments. ${ }^{84}$ In addition, the alternative interpretation of a key role for 'accelerated' growth has gained more prominence.$^{85}$ Moreover, although fetal and infant life are undoubtedly critical windows of development with very rapid growth, others have highlighted the role of cumulative exposures throughout $\operatorname{life}^{86}$ and perhaps especially childhood, whilst yet others have recently drawn attention to another hitherto overlooked phase of rapid growth, i.e. puberty. ${ }^{69}$

The "mismatch" theory suggests that the fetus uses environmental cues to make a predictive adaptive response which 'tunes' its phenotype for the expected environment, but which may result in increased metabolic risk for babies who subsequently encounter more plentiful conditions. ${ }^{84}$ This theory is intuitively appealing and specifically relevant to countries undergoing very rapid economic transition, such as China, where large differences in living conditions between generations, and a mother's relatively poor growth environment, 'constitution' and 'build' might condition her offspring for "thriftiness" and hence result in increased metabolic risk in subsequent living conditions with a more plentiful food supply and sedentary lifestyle. Although, this theory is under-pinned by a large body of evidence concerning birth weight and metabolic disease or its consequences, effects are relatively small, ${ }^{83}$ and specific evidence that a greater degree of mismatch between fetal and adult environment generates metabolic disease is sparse, ${ }^{84}$ partly because the theory is hard to operationalize and investigate in the developing populations most likely to experience mismatch.

In contrast, the accelerated growth hypothesis stresses the role of over-nutrition in early infancy as a critical window. For example the first few weeks of life may be a critical time for setting regulation of appetite and satiety, susceptible to disruption by over-feeding.$^{87}$ The theory is supported by experimental evidence in mainly premature babies. ${ }^{85}$ Observational evidence from many settings, including in Chinese, also shows 
that more rapid infant growth is associated with higher childhood body mass index (BMI) ${ }^{88: 89}$ such that Chinese boys who gained weight rapidly between birth and 3 months (equivalent to going from the $25^{\text {th }}$ to the $50^{\text {th }}$ centile or similar on a growth chart) approximately doubled their risk of being overweight or obese at 7 years, whilst Chinese girls with similarly rapid growth increased their risk by almost $50 \%{ }^{89}$ Childhood BMI is in turn associated with cardiovascular risk in adult life. ${ }^{90}$ Moreover, evidence from both developed settings and China shows that a marker of more rapid growth from infancy through childhood, i.e. earlier sexual maturity, is associated with increased metabolic risk, ${ }^{91 ; 92}$ although inevitably there is more evidence for girls than boys, because of the relative ease of collecting proxies of sexual maturation in girls than boys. In one large recent study from China, older women with menarche before the age of 12.5 years had $49 \%$ higher odds of the metabolic syndrome than women with menarche at 14.5 years or older. ${ }^{92}$ If 'accelerated' growth is a risk factor, the increasingly plentiful conditions in China since 1949, as shown by increases in height ${ }^{93}$ and decreases in the age of menarche, ${ }^{94}$ may have already contributed to an immutable increase in the risk of the metabolic syndrome.

Theories concerning the role of cumulative disadvantage stem from the observation that childhood deprivation and its proxies, such as shorter legs or shorter height, are associated with diseases for which the metabolic syndrome may be a sentinel. ${ }^{81 ; 95}$ Almost all the evidence on this topic comes from long-term industrialized populations. More limited evidence from other locations with more recent histories of economic development suggest that the association between poor childhood conditions and stroke may be universal ${ }^{96}$ whilst the association between poor childhood conditions and the metabolic syndrome or its proxies is less clear, ${ }^{79 ; 96}$ especially for obesity in men. ${ }^{69}$ Given that the mechanism responsible for the association between poor childhood conditions and later metabolic risk has not been clearly specified, this theory does not shed any light on why these epidemiologic stage specific findings are occurring. In contrast, a recent, biologically based theory proposes that dietary-driven levels of sex-steroids at puberty permanently increase sexual dimorphism in body shape and lipids with opposite effects by sex, but has less effect on diabetes risk, because its pre-cursors are more strongly related to another hypothalamic-pituitaryendocrine axis, i.e. growth hormone. ${ }^{97}$ This theory implies that growing up in poor conditions should be associated with central obesity and dyslipidemia in women, but conversely growing up in better conditions should be associated with central obesity and dyslipidemia in men, consistent with some recent studies from China. ${ }^{69: 97}$ This theory is consistent with the observed emergence of an epidemic of coronary heart disease, but not diabetes, in western men with economic development. ${ }^{9 ; 98}$ However, although the theory does no more than state the implications over historical time of known biological processes it is not congruent with the 'common soil' hypothesis.

Distinguishing between these theories and correctly identifying the critical period (if any) and the nature of the exposure (under or over) nutrition is critically important to developing potentially vital public health interventions for the generations growing up in China today and their offspring. Currently, given the 
epidemic of childhood obesity also emerging in China, ${ }^{99}$ and the likely tracking of risk factors into adulthood $^{100}$ it would appear that early life might be a key target of intervention. It is thus vital to clarify the role of growth and nutrition from conception onwards on all aspects of metabolic risk in a developing country context, so as to take account of any differences arising from epidemiological stage or population history.

\section{Conclusion}

Currently there is an epidemic of metabolic disease in China, undoubtedly fuelled by the greater availability of more palatable foods and decreases in physical activity facilitated by recent economic development. Chinese people may be genetically more susceptible to the metabolic consequences of an obesogenic environment, or they may be conditioned by their history of very recent development to be both psychologically and physiology more vulnerable, because of cultural norms, lifetime experiences and the inter-generational transmission of risk via epigenetic processes. Identifying the relative importance and mutability of epigenetic processes, influences over the life course and current environment is key to developing effective public health interventions during the current 'demographic window' before the costs of metabolic disease become overwhelming. 


\section{Reference List}

1. Maddison A. The world economy: a millennial perspective. Paris: Development Centre of the Organisation for Economic Co-operation and Development; 2001.

2. Zhao W, Chen J. Implications from and for food cultures for cardiovascular disease: diet, nutrition and cardiovascular diseases in China. [Review] [13 refs]. Asia Pacific Journal of Clinical Nutrition 2001; 10(2): 146-152.

3. Geissler C. China: the soyabean-pork dilemma. [Review] [54 refs]. Proceedings of the Nutrition Society 1999; 58(2): 345-353.

4. Pan XR, Yang WY, Li GW, Liu J. Prevalence of diabetes and its risk factors in China, 1994. National Diabetes Prevention and Control Cooperative Group. Diabetes Care 1997; 20(11): 1664-1669.

5. Gu D, Reynolds K, Duan X, Xin X, Chen J, Wu Xet al. Prevalence of diabetes and impaired fasting glucose in the Chinese adult population: International Collaborative Study of Cardiovascular Disease in Asia (InterASIA). Diabetologia 2003; 46(9): 1190-1198.

6. Lee WR. The changing demography of diabetes mellitus in Singapore. Diabetes Res Clin Pract 2000; 50 Suppl 2:S35-9.): S35-S39.

7. He J, Gu D, Wu X, Reynolds K, Duan X, Yao Cet al. Major causes of death among men and women in China. N Engl J Med 2005; 353(11): 1124-1134.

8. Liu M, Wu B, Wang WZ, Lee LM, Zhang SH, Kong LZ. Stroke in China: epidemiology, prevention, and management strategies. Lancet Neurol 2007; 6(5): 456-464.

9. Lawlor DA, Ebrahim S, Smith GD. Sex matters: secular and geographical trends in sex differences in coronary heart disease mortality. BMJ 2001; 323(7312): 541-545.

10. Lawlor DA, Smith GD, Leon DA, Sterne JA, Ebrahim S. Secular trends in mortality by stroke subtype in the 20th century: a retrospective analysis. Lancet 2002; 360(9348): 1818-1823.

11. Batsis JA, Nieto-Martinez RE, Lopez-Jimenez F. Metabolic syndrome: from global epidemiology to individualized medicine. Clin Pharmacol Ther 2007; 82(5): 509-524.

12. Ford ES. Risks for all-cause mortality, cardiovascular disease, and diabetes associated with the metabolic syndrome: a summary of the evidence. Diabetes Care 2005; 28(7): 1769-1778.

13. Galassi A, Reynolds K, He J. Metabolic syndrome and risk of cardiovascular disease: a metaanalysis. Am J Med 2006; 119(10): 812-819.

14. Gami AS, Witt BJ, Howard DE, Erwin PJ, Gami LA, Somers VKet al. Metabolic syndrome and risk of incident cardiovascular events and death: a systematic review and meta-analysis of longitudinal studies. J Am Coll Cardiol 2007; 49(4): 403-414.

15. Thomas GN, Schooling CM, McGhee SM, Ho SY, Cheung BM, Wat NMet al. Metabolic syndrome increases vascular and all-cause mortality: the Hong Kong Cardiovascular Risk Factor Study. Clinical Endrocrinology 2007; 66(5): 666-671.

16. Wang JJ, Li HB, Kinnunen L, Hu G, Jarvinen TM, Miettinen MEet al. How well does the metabolic syndrome defined by five definitions predict incident diabetes and incident coronary heart disease in a Chinese population? Atherosclerosis 2007; 192(1): 161-168.

17. Patel A, Barzi F, Woodard M, Ni MC, Ohkubo T, Lam THet al. An evaluation of metabolic risks for coronary death in the Asia Pacific region. Diabetes Res Clin Pract 2006; 74(3): 274281.

18. Wannamethee SG, Shaper AG, Lennon L, Morris RW. Metabolic syndrome vs Framingham Risk Score for prediction of coronary heart disease, stroke, and type 2 diabetes mellitus. Arch Intern Med 2005; 165(22): 2644-2650.

19. Reaven GM. The metabolic syndrome: is this diagnosis necessary? Am J Clin Nutr 2006; 83(6): 1237-1247.

20. Grundy SM. Does a diagnosis of metabolic syndrome have value in clinical practice? Am J Clin Nutr 2006; 83(6): 1248-1251.

21. Ford ES. Prevalence of the metabolic syndrome defined by the International Diabetes Federation among adults in the U.S. Diabetes Care 2005; 28(11): 2745-2749. 
22. Yang W, Reynolds K, Gu D, Chen J, He J. A comparison of two proposed definitions for metabolic syndrome in the Chinese adult population. Am J Med Sci 2007; 334(3): 184189.

23. Reaven GM. Banting lecture 1988. Role of insulin resistance in human disease. Diabetes 1988; 37(12): 1595-1607.

24. Kahn R, Buse J, Ferrannini E, Stern M. The metabolic syndrome: time for a critical appraisal. Joint statement from the American Diabetes Association and the European Association for the Study of Diabetes. Diabetologia 2005; 48(9): 1684-1699.

25. Despres JP, Lemieux I. Abdominal obesity and metabolic syndrome. Nature 2006; 444(7121): 881-887.

26. Zhao D, Grundy SM, Wang W, Liu J, Zeng Z, Wang Wet al. Ten-year cardiovascular disease risk of metabolic syndrome without central obesity in middle-aged chinese. Am J Cardiol 2007; 100(5): 835-839.

27. Lawlor DA, Ebrahim S, May M, Davey SG. (Mis)use of factor analysis in the study of insulin resistance syndrome. Am J Epidemiol 2004; 159(11): 1013-1018.

28. Anderson PJ, Critchley JA, Chan JC, Cockram CS, Lee ZS, Thomas GNet al. Factor analysis of the metabolic syndrome: obesity vs insulin resistance as the central abnormality. Int J Obes Relat Metab Disord 2001; 25(12): 1782-1788.

29. Pladevall M, Singal B, Williams LK, Brotons C, Guyer H, Sadurni Jet al. A single factor underlies the metabolic syndrome: a confirmatory factor analysis. Diabetes Care 2006; 29(1): 113-122.

30. Wang LD. Comprehensive report, Chinese nutrition and health survey in 2002. Beijing: People's Medical Publishing House; 2005.

31. Yue TX, Wang YA, Liu JY, Chen SP, Qiu DS, Deng XZet al. Surface modelling of human population distribution in China. Ecological Modelling 2005; 181(4): 461-478.

32. Wang SY, Chi GB, Jing CX, Dong XM, Wu CP, Li LP. Trends in road traffic crashes and associated injury and fatality in the People's Republic of China, 1951-1999. Inj Control Saf Promot 2003; 10(1-2): 83-87.

33. Bell AC, Ge K, Popkin BM. The road to obesity or the path to prevention: motorized transportation and obesity in China. Obes Res 2002; 10(4): 277-283.

34. Keith SW, Redden DT, Katzmarzyk PT, Boggiano MM, Hanlon EC, Benca RMet al. Putative contributors to the secular increase in obesity: exploring the roads less traveled. Int J Obes (Lond) 2006; 30(11): 1585-1594.

35. Hu FB, Wang B, Chen C, Jin Y, Yang J, Stampfer MJet al. Body mass index and cardiovascular risk factors in a rural Chinese population. Am J Epidemiol 2000; 151(1): 88-97.

36. Shai I, Schwarzfuchs D, Henkin Y, Shahar DR, Witkow S, Greenberg Iet al. Weight loss with a low-carbohydrate, Mediterranean, or low-fat diet. N Engl J Med 2008; 359(3): 229-241.

37. Meckling KA, Sherfey R. A randomized trial of a hypocaloric high-protein diet, with and without exercise, on weight loss, fitness, and markers of the Metabolic Syndrome in overweight and obese women. Appl Physiol Nutr Metab 2007; 32(4): 743-752.

38. Hebert JR, Clemow L, Pbert L, Ockene IS, Ockene JK. Social desirability bias in dietary selfreport may compromise the validity of dietary intake measures. Int J Epidemiol 1995; 24(2): 389-398.

39. Kipnis V, Midthune D, Freedman L, Bingham S, Day NE, Riboli Eet al. Bias in dietary-report instruments and its implications for nutritional epidemiology. Public Health Nutr 2002; 5(6A): 915-923.

40. Yao M, McCrory MA, Ma G, Tucker KL, Gao S, Fuss Pet al. Relative influence of diet and physical activity on body composition in urban Chinese adults. Am J Clin Nutr 2003; 77(6): 1409-1416.

41. Grundy SM, Abate N, Chandalia M. Diet composition and the metabolic syndrome: what is the optimal fat intake? Am J Med 2002; 113 Suppl 9B:25S-29S.): 25S-29S.

42. Riserus U, Arnlov J, Berglund L. Long-term predictors of insulin resistance: role of lifestyle and metabolic factors in middle-aged men. Diabetes Care 2007; 30(11): 2928-2933.

43. Shah M, ms-Huet B, Garg A. Effect of high-carbohydrate or high-cis-monounsaturated fat diets on blood pressure: a meta-analysis of intervention trials. Am J Clin Nutr 2007; 85(5): 12511256. 
44. Villegas R, Liu S, Gao YT, Yang G, Li H, Zheng Wet al. Prospective study of dietary carbohydrates, glycemic index, glycemic load, and incidence of type 2 diabetes mellitus in middle-aged Chinese women. Arch Intern Med 2007; 167(21): 2310-2316.

45. Campbell TC, Chen J. Energy balance: interpretation of data from rural China. Toxicol Sci 1999; 52(2 Suppl): 87-94.

46. Ng SW, Zhai F, Popkin BM. Impacts of China's edible oil pricing policy on nutrition. Soc Sci Med 2008; 66(2): 414-426.

47. Baxter AJ, Coyne T, McClintock C. Dietary patterns and metabolic syndrome--a review of epidemiologic evidence. Asia Pac J Clin Nutr 2006; 15(2): 134-142.

48. Villegas R, Shu XO, Gao YT, Yang G, Cai H, Li Het al. The association of meat intake and the risk of type 2 diabetes may be modified by body weight. Int J Med Sci 2006; 3(4): 152159.

49. Tholstrup T. Dairy products and cardiovascular disease. Curr Opin Lipidol 2006; 17(1): 1-10.

50. Moss M, Freed D. The cow and the coronary: epidemiology, biochemistry and immunology. Int J Cardiol 2003; 87(2-3): 203-216.

51. Yang Y, He M, Cui H, Bian L, Wang Z. The prevalence of lactase deficiency and lactose intolerance in Chinese children of different ages. Chin Med J (Engl ) 2000; 113(12): 1129-1132.

52. Yang G, Fan L, Tan J, Qi G, Zhang Y, Samet JMet al. Smoking in China: Findings of the 1996 National Prevalence Survey. JAMA 1999; 282(13): 1247-1253.

53. Hao W, Chen H, Su Z. China: alcohol today. Addiction 2005; 100(6): 737-741.

54. Lau EM, Lee P, Lynn H, Sham A, Woo J. The epidemiology of cigarette smoking in Hong Kong Chinese women. Prev Med 2003; 37(5): 383-388.

55. Wannamethee SG, Shaper AG, Whincup PH. Modifiable lifestyle factors and the metabolic syndrome in older men: Effects of lifestyle changes. J Am Geriatr Soc 2006; 54(12): 1909-1914.

56. Gronbaek M. Alcohol, type of alcohol, and all-cause and coronary heart disease mortality. Ann N Y Acad Sci 2002; 957:16-20.): 16-20.

57. Reynolds K, Lewis B, Nolen JD, Kinney GL, Sathya B, He J. Alcohol consumption and risk of stroke: a meta-analysis. JAMA 2003; 289(5): 579-588.

58. Carlsson S, Hammar N, Grill V. Alcohol consumption and type 2 diabetes Meta-analysis of epidemiological studies indicates a U-shaped relationship. Diabetologia 2005; 48(6): 1051-1054.

59. Yuan JM, Ross RK, Gao YT, Henderson BE, Yu MC. Follow up study of moderate alcohol intake and mortality among middle aged men in Shanghai, China. BMJ 1997; 314(7073): 18-23.

60. Xu WH, Zhang XL, Gao YT, Xiang YB, Gao LF, Zheng Wet al. Joint effect of cigarette smoking and alcohol consumption on mortality. Prev Med 2007; 45(4): 313-319.

61. Chen L, Smith GD, Harbord RM, Lewis SJ. Alcohol intake and blood pressure: a systematic review implementing a Mendelian randomization approach. PLoS Med 2008; 5(3): e52.

62. Zilkens RR, Burke V, Watts G, Beilin LJ, Puddey IB. The effect of alcohol intake on insulin sensitivity in men: a randomized controlled trial. Diabetes Care 2003; 26(3): 608-612.

63. Baer DJ, Judd JT, Clevidence BA, Muesing RA, Campbell WS, Brown EDet al. Moderate alcohol consumption lowers risk factors for cardiovascular disease in postmenopausal women fed a controlled diet. Am J Clin Nutr 2002; 75(3): 593-599.

64. Marmot MG. Status syndrome: a challenge to medicine. JAMA 2006; 295(11): 1304-1307.

65. Wilkinson RG, Pickett KE. The problems of relative deprivation: why some societies do better than others. Soc Sci Med 2007; 65(9): 1965-1978.

66. Kawachi I, Kennedy BP. Health and social cohesion: why care about income inequality? BMJ 1997; 314(7086): 1037-1040.

67. Yu Z, Nissinen A, Vartiainen E, Song G, Guo Z, Tian H. Changes in cardiovascular risk factors in different socioeconomic groups: seven year trends in a Chinese urban population. J Epidemiol Community Health 2000; 54(9): 692-696.

68. Xu F, Yin XM, Zhang M, Leslie E, Ware R, Owen N. Family average income and diagnosed Type 2 diabetes in urban and rural residents in regional mainland China. Diabet Med 2006; 23(11): 1239-1246. 
69. Schooling CM, Jiang CQ, Lam T.H., Zhang W, Cheng KK, Leung GM. Life-Course Origins of Social Inequalities in Metabolic risk in the Population of a Developing Country. AJE 2008; 167(4): 419-428.

70. Edwards KL, Newman B, Mayer E, Selby JV, Krauss RM, Austin MA. Heritability of factors of the insulin resistance syndrome in women twins. Genet Epidemiol 1997; 14(3): 241-253.

71. Chen W, Srinivasan SR, Elkasabany A, Berenson GS. The association of cardiovascular risk factor clustering related to insulin resistance syndrome (Syndrome $\mathrm{X}$ ) between young parents and their offspring: the Bogalusa Heart Study. Atherosclerosis 1999; 145(1): 197205.

72. Chang YC, Liu PH, Lee WJ, Chang TJ, Jiang YD, Li HYet al. Common variation in the fat mass and obesity-associated (FTO) gene confers risk of obesity and modulates BMI in the Chinese population. Diabetes 2008; 57(8): 2245-2252.

73. Li H, Wu Y, Loos RJ, Hu FB, Liu Y, Wang Jet al. Variants in the fat mass- and obesityassociated (FTO) gene are not associated with obesity in a Chinese Han population. Diabetes 2008; 57(1): 264-268.

74. Lear SA, Humphries KH, Kohli S, Chockalingam A, Frohlich JJ, Birmingham CL. Visceral adipose tissue accumulation differs according to ethnic background: results of the Multicultural Community Health Assessment Trial (M-CHAT). Am J Clin Nutr 2007; 86(2): 353-359.

75. Benyshek DC, Watson JT. Exploring the thrifty genotype's food-shortage assumptions: a crosscultural comparison of ethnographic accounts of food security among foraging and agricultural societies. Am J Phys Anthropol 2006; 131(1): 120-126.

76. Wolf JB, Hager R. A Maternal-Offspring Coadaptation Theory for the Evolution of Genomic Imprinting. PLoS Biol 2006; 4(12): e380.

77. Schooling CM, Jiang CQ, Heys M, Zhang W, Adab P, Cheng KKet al. Are height and leg length universal markers of childhood conditions? The Guangzhou Biobank Cohort Study. JECH 2008; 62(7): 607-614.

78. Luo ZC, Cheung YB, He Q, Albertsson-Wikland K, Karlberg J. Growth in early life and its relation to pubertal growth. Epidemiology 2003; 14(1): 65-73.

79. Schooling CM, Jiang C, Lam TH, Thomas GN, Heys M, Lao Xet al. Height, its components and cardiovascular risk in older Chinese: a cross-sectional analysis of The Guangzhou Biobank Cohort Study. Am J Public Health 2007; 18(10): 1834-1841.

80. Lawlor DA, Ebrahim S, Davey SG. The association between components of adult height and Type II diabetes and insulin resistance: British Women's Heart and Health Study. Diabetologia 2002; 45(8): 1097-1106.

81. Asao K, Kao WH, Baptiste-Roberts K, Bandeen-Roche K, Erlinger TP, Brancati FL. Short Stature and the Risk of Adiposity, Insulin Resistance, and Type 2 Diabetes in Middle Age: The Third National Health and Nutrition Examination Survey (NHANES III), 1988-1994. Diabetes Care 2006; 29(7): 1632-1637.

82. Humphreys M, Costanzo P, Haynie KL, Ostbye T, Boly I, Belsky Det al. Racial disparities in diabetes a century ago: evidence from the pension files of US Civil War veterans. Soc Sci Med 2007; 64(8): 1766-1775.

83. Huxley R, Neil A, Collins R. Unravelling the fetal origins hypothesis: is there really an inverse association between birthweight and subsequent blood pressure? Lancet 2002; 360(9334): 659-665.

84. Gluckman P, Hanson M. Mismatch: Why our bodies no longer fit our world. Oxford: OUP; 2006.

85. Singhal A, Lucas A. Early origins of cardiovascular disease: is there a unifying hypothesis? Lancet 2004; 363(9421): 1642-1645.

86. Smith GD, Ben-Shlomo Y, Lynch J. Life course approaches to inequalities in coronary heart disease risk. In: Stansfeld SA and Marmot MGeds. Stress and the heart : psychosocial pathways to coronary heart disease. London: BMJ Books; 2002;21-49.

87. Plagemann A. Perinatal nutrition and hormone-dependent programming of food intake. Horm Res 2006; 65 Suppl 3): 83-89.

88. Baird J, Fisher D, Lucas P, Kleijnen J, Roberts H, Law C. Being big or growing fast: systematic review of size and growth in infancy and later obesity. BMJ 2005; 331(7522): 929. 
89. Hui LL, Schooling CM, Leung SSL, Mak KH, Ho L.M., Lam T.H.et al. Birth weight, infant growth and childhood body mass index: Hong Kong's Children of 1997 birth cohort. APAM 2008; 162(3): 212-218.

90. Baker JL, Olsen LW, Sorensen TI. Childhood body-mass index and the risk of coronary heart disease in adulthood. N Engl J Med 2007; 357(23): 2329-2337.

91. Frontini MG, Srinivasan SR, Berenson GS. Longitudinal changes in risk variables underlying metabolic Syndrome X from childhood to young adulthood in female subjects with a history of early menarche: the Bogalusa Heart Study. Int J Obes Relat Metab Disord 2003; 27(11): 1398-1404.

92. Heys M, Schooling CM, Jiang CQ, Cowling BJ, Lao X, Zhang Wet al. Age of menarche and the metabolic syndrome in China: The Guangzhou Biobank Cohort Study. Epidemiology 2007; 18 (6): 740-746.

93. Lei S, Yong-Yong X, Xun J, Xiao-Han D. Geographical differences in physiques of male youth of age 18-20 years in China. Am J Hum Biol 2006; 18(1): 141-148.

94. Hesketh T, Ding QJ, Tomkins A. Growth status and menarche in urban and rural China. Ann Hum Biol 2002; 29(3): 348-352.

95. Galobardes B, Smith GD, Lynch JW. Systematic review of the influence of childhood socioeconomic circumstances on risk for cardiovascular disease in adulthood. Ann Epidemiol 2006; 16(2): 91-104.

96. Song YM, Smith GD, Sung J. Adult height and cause-specific mortality: a large prospective study of South Korean men. Am J Epidemiol 2003; 158(5): 479-485.

97. Schooling CM, Lam T.H., Thomas GN, Cowling BJ, Heys M, Janus EDet al. Growth environment and sex differences in lipids, body shape and diabetes risk. PlosOne 2007; 2(10): e1070 .

98. Gale EA, Gillespie KM. Diabetes and gender. Diabetologia 2001; 44(1): 3-15.

99. Ji CY. Report on childhood obesity in China (4) prevalence and trends of overweight and obesity in Chinese urban school-age children and adolescents, 1985-2000. Biomed Environ Sci 2007; 20(1): 1-10.

100. Ovesen L. Adolescence: a critical period for long-term tracking of risk for coronary heart disease? Ann Nutr Metab 2006; 50(4): 317-324. 